\title{
The effects of cigarette smoking on cardiopulmonary function and exercise tolerance in teenagers
}

\author{
Dianna Louie \\ Sir Winston Churchill Secondary School and the University of British Columbia McDonald \\ Research Laboratories, St Paul's Hospital, Vancouver, British Columbia
}

\begin{abstract}
D Louie. The effects of cigarette smoking on cardiopulmonary function and exercise tolerance in teenagers. Can Respir J 2001;8(4):289-291.
\end{abstract}

Teenagers who smoke are frequently warned that cigarette smoking will have detrimental effects on the function of their cardiopulmonary system and on their ability to perform exercise. However, there is little published evidence to support this statement. Therefore, in the present study, peak expiratory flow was measured as an indicator of lung function, expired carbon monoxide level was measured as an indicator of current smoking and the associated reduction in the oxygen carrying capacity of the blood, and blood pressure and heart rate were measured as indicators of cardiovascular hemodynamics before and after a one-mile run in 27 teenagers. The results show that, even at a young age, cigarette smoking is associated with significant detrimental effects on cardiopulmonary function and exercise tolerance. Objective evidence of an effect of smoking on cardiopulmonary function and exercise tolerance in this age group may assist educators and health care professionals in convincing teenagers to quit smoking.

Key Words: Cardiopulmonary function; Exercise; Smoking; Teenagers; Tobacco

\section{Effets du tabagisme sur le fonctionnement cardio-pulmonaire et la tolérance à l'effort chez les adolescents}

RÉSUMÉ : On dit souvent aux adolescents qui fument que leur habitude peut être préjudiciable au fonctionnement de l'appareil cardio-pulmonaire et à la capacité d'effectuer un effort, mais l'on dispose de peu de données publiées pour étayer l'assertion. Aussi avons-nous mesuré, dans le cadre de la présente étude, le débit expiratoire de pointe comme indice du fonctionnement pulmonaire, la quantité d'oxyde de carbone expiré comme indice du degré de tabagisme et, par le fait même, de la diminution de la capacité de transport de l'oxygène dans le sang ainsi que la pression artérielle et la fréquence cardiaque comme indices de l'hémodynamique cardiovasculaire chez 27 adolescents avant et après qu'ils eurent couru 1,6 km (1 mille). Il ressort de l'étude que le tabagisme, même à un jeune âge, est associé à d'importants effets néfastes sur le fonctionnement cardio-pulmonaire et la tolérance à l'effort. Des données objectives confirmant la diminution de la capacité cardio-pulmonaire chez les jeunes peuvent aider les éducateurs et les professionnels de la santé à les convaincre à abandonner le tabagisme.

Correspondence and reprints: Ms Dianna Louie clo Dr Peter D Paré, McDonald Research Laboratories, Room 292, St Paul's Hospital, 1081 Burrard Street, Vancouver, British Columbia V6T 1Y6. Telephone 604-682-2344 ext 2750, fax 604-806-8674,

e-mailppare@mrl.ubc.ca 
$\mathrm{C}$ hronic cigarette smoking is the most important risk factor for the development of chronic obstructive pulmonary disease, and it is a significant risk factor for cardiovascular disease. In addition to these well-documented long term risks, teenagers who smoke are frequently warned that cigarette smoking will have a detrimental effect on cardiopulmonary function and exercise tolerance, and thus, their ability to engage in sporting activities. However, there is little published evidence that young smokers have decreased fitness. Because of this lack of evidence, I undertook a study to assess the effects of cigarette smoking on cardiopulmonary function and exercise tolerance in grade 10 students between the ages of 14 and 16 years. Smoking may reduce exercise capacity by interfering with lung function, by interfering with the oxygen carrying capacity of the blood, or by influencing systemic and/or pulmonary hemodynamics. Therefore, I measured peak expiratory flow as an indicator of lung function, expired carbon monoxide level as a measure of current smoking and the associated reduction in oxygen carrying capacity of the blood, and blood pressure and heart rate as indicators of cardiovascular hemodynamics. The results show that, even at this young age, cigarette smoking is associated with significant detrimental effects on cardiopulmonary function and exercise tolerance. Objective evidence of an effect of smoking on cardiopulmonary function in this age group may assist educators and health care professionals in convincing teenagers to quit smoking.

\section{SUBJECTS AND METHODS}

The subjects for this study were 27 teenagers chosen from the grade 10 population at Sir Winston Churchill Secondary School, Vancouver, British Columbia. All of the author's classmates were invited to participate, and all students who were interested in participating were studied. Twelve of the subjects were smokers and 15 were lifetime nonsmokers. All subjects completed a one-mile, timed run on a $400 \mathrm{~m}$ track. Before the run, peak expiratory flow, blood pressure and heart rate were measured in all subjects; the measurements were repeated in the same order immediately after cessation of the run. A portable peak flow meter (Breathalert, Carestream Medical, Australia and New Zealand) was used to test the maximal expiratory flow before and after the run. After the subjects were trained to use the peak expiratory flow meter, three maximal expiratory efforts were obtained, and the highest peak expiratory flow value was used for analysis. A similar protocol was used postrun. The heart rate was measured pre- and postexercise by counting the radial artery pulse rate for $1 \mathrm{~min}$. Systemic blood pressure was measured using an automated cuff (Dynamap 1846, Critikon, USA). The systolic, diastolic and mean blood pressures were recorded, and the mean pressure is reported here (Table 1). An estimate of the blood carboxyhemoglobin concentration was measured on a separate occasion using the mini Smokerlyzer (Benfont Technical Instruments Limited, United Kingdom), and the results were expressed as parts per million. Two reproducible measurements were obtained on each subject, and the values were averaged. Cardiopulmonary fitness was assessed using
TABLE 1

Anthropometric and physiological data (mean \pm SD) of 27 subjects participating in a study of the effects of smoking on cardiopulmonary function and exercise tolerance in teenagers

\begin{tabular}{lcc}
\hline & Nonsmokers & Smokers \\
\hline Number of subjects & 15 & 12 \\
Age (years) & $14.9 \pm 0.5$ & $15.2 \pm 0.7$ \\
Male/female & $7 / 8$ & $7 / 5$ \\
Pack-years & - & $1.53 \pm 1.48$ \\
Height (cm) & $169.8 \pm 9.8$ & $167.9 \pm 7.5$ \\
Baseline peak flow (L/min) & $467 \pm 92.5$ & $410 \pm 82$ \\
Baseline mean arterial & $98.2 \pm 9.9$ & $98.5 \pm 13.1$ \\
$\quad$ pressure (mmHg) & & \\
Baseline heart rate & $85.6 \pm 14.5$ & $90.8 \pm 10.5$ \\
$\quad$ (beats/min) & & \\
\hline
\end{tabular}

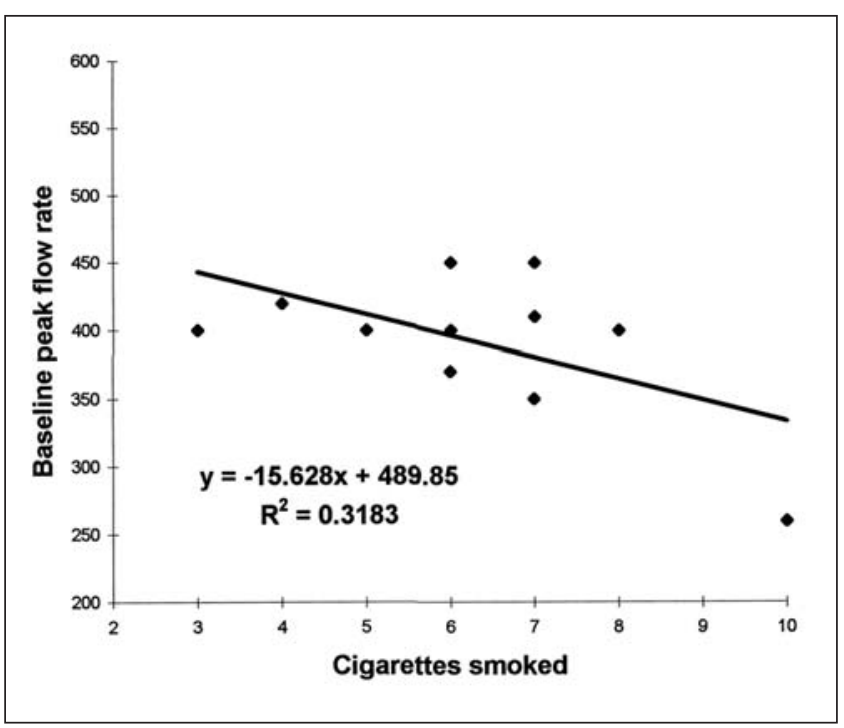

Figure 1) The correlation between cigarettes smoked per day and baseline peak flow rate

a questionnaire regarding the involvement of the subject in sports and/or regular exercise programs.

Statistical analysis: Baseline data in smokers and nonsmokers, and physiological parameters pre- and postexercise, were compared using Student's $t$ tests for paired and unpaired data. The results were considered significant at $\mathrm{P}<0.05$. The relationships between selected variables were tested using linear regression analysis.

\section{RESULTS}

Baseline anthropometric and physiological data on the subjects are shown in Table 1 . There were no significant differences between the two groups except for their smoking history. There was a significant correlation between the baseline peak flow rate and the number of cigarettes smoked per day $(\mathrm{r}=0.56)$ among the smokers (Figure 1).

All of the subjects completed the one-mile run. The non- 
TABLE 2

Physiological measurements of 27 subjects participating in a study of the effects of smoking on cardiopulmonary function and exercise tolerance in teenagers

\begin{tabular}{lcc}
\hline & Nonsmokers & Smokers \\
\hline $\begin{array}{l}\text { Run time (min) } \\
\text { Changes in peak expiratory }\end{array}$ & $8.8 \pm 2.7$ & $10.5 \pm 2.5^{*}$ \\
$\quad$ flow (L/min) & $0.66 \pm 34.8$ & $-34 \pm 58.2^{*}$ \\
$\begin{array}{l}\text { Changes in mean arterial } \\
\text { pressure (mmHg) }\end{array}$ & $1.1 \pm 12.2$ & $8.4 \pm 18.7^{\dagger}$ \\
Changes in heart rate (beats/min) & $42 \pm 18$ & $31 \pm 9.8^{\dagger}$ \\
\hline
\end{tabular}

${ }^{*}$ Significant; ${ }^{\dagger}$ Not significant

smokers finished significantly faster than the smokers, and there was a significant decrease in the peak expiratory flow from pre- to postrun in the smokers, while no change was found in the nonsmokers. The subjects' heart rates increased in both groups but there was no significant difference, and although blood pressure increased more in smokers than in nonsmokers postrun, this difference did not achieve statistical significance $(\mathrm{P}=0.07)$. The results of the run time, and the changes in peak expiratory flow, mean arterial pressure and heart rate pre- to postrun, are reported in Table 2. There was a significant correlation between the baseline peak expiratory flow rate and the run time ( $\mathrm{r}=0.67)$ for all subjects.

The mean expired carbon monoxide concentration in the nonsmokers was $1.9 \pm 0.9$ parts/million compared with $14.3 \pm 2.5$ parts/million in the smokers $(\mathrm{P}<0.05)$. Nonsmokers were more likely to be involved in regular sporting activities, but were not more likely than smokers to be engaged in a regular fitness program (Table 3).

\section{DISCUSSION}

The results of the present study show that there are significant differences in cardiopulmonary function and exercise tolerance between adolescent smokers and nonsmokers, even though the mean pack-years among the smokers was only $1.53 \pm 1.48$. As expected, smokers had higher levels of exhaled carbon monoxide than nonsmokers. In addition, the results show that smokers, as opposed to nonsmokers, develop a significant reduction in peak expiratory flow after a short period of exercise. There was also a tendency for smokers to develop a larger increase in the mean systemic arterial pressure postexercise.

The significantly increased run time observed among the smokers could be related to a number of factors. First, as indicated in Table 3, smokers were less likely to be engaged in regular sporting activities; it is unclear whether there is a causal relationship between these two observations. In other words, do smokers avoid sporting activities because they are less fit or are they less fit because they do not engage in sporting activities? The results of the present study cannot address which of these possibilities is true. The longer run time
TABLE 3

Fitness activities of 27 subjects participating in a study of the effects of smoking on cardiopulmonary function and exercise tolerance in teenagers

\begin{tabular}{lcccc}
\hline & \multicolumn{2}{c}{ Nonsmokers } & \multicolumn{2}{c}{ Smokers } \\
& Yes & No & Yes & No \\
\hline $\begin{array}{l}\text { Regular sporting } \\
\begin{array}{l}\text { activities } \\
\text { Fitness program }\end{array}\end{array}$ & 10 & 5 & 3 & 9 \\
\hline
\end{tabular}

among the smokers could also be related to their higher carboxyhemoglobin level and/or the development of bronchoconstriction during exercise.

The most surprising finding in the present study is the significant difference in the response of peak expiratory flow to the exercise challenge. It is well known that patients who have asthma and chronic obstructive pulmonary disease may develop bronchoconstriction after exercise $(1,2)$. In addition, a number of studies have shown that a substantial percentage of high school athletes develop exercise-induced bronchoconstriction $(3,4)$. However, to my knowledge, this is the first report of a significant effect of a short exercise protocol on peak expiratory flow in asymptomatic adolescent smokers. These results suggest that an effect of smoking on the airways occurs after a relatively short exposure.

There are few experimental data in the literature addressing the differences in exercise tolerance and lung function in adolescents who smoke to the degree reported in this study. Although parents, teachers and health care professionals frequently counsel adolescents that smoking will influence their level of fitness, a lack of objective evidence makes the weight of this message less than convincing. The results of the present study, which indicate that significant differences in exercise tolerance and lung function can be detected in smokers at an early stage, should help educators and health care professionals to convince adolescents to stop smoking or to refrain from starting smoking.

ACKNOWLEDGEMENTS: I acknowledge the support of Dr Peter Paré, Ms Barbara Moore, Dr Geoff Gabbot, Mr Kim Parrish, Ms Kerri Hornbi, Ms Christen Oram, Dr Gillian Arsenault, Mr Ken Louie and Dr Heather Louie.

\section{REFERENCES}

1. Inman MD. Management of exercise-induced bronchoconstriction. Can Respir J 1999;6:345-54.

2. Cox NJ, van Herwaarden CL, Folgering H, Binkhorst RA. Exercise and training in patients with chronic obstructive lung disease. Sports Med 1988;6:180-92.

3. Kukafka DS, Lang DM, Porter S, et al. Exercise-induced bronchospasm in high school athletes via a free running test: incidence and epidemiology. Chest 1998;114:1613-22.

4. Rupp NT, Guill MF, Brudno DS. Unrecognized exercise-induced bronchospasm in adolescent athletes. Am J Dis Child 1992;146:941-4. 


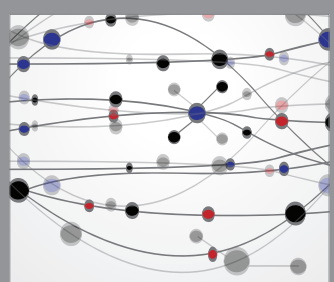

The Scientific World Journal
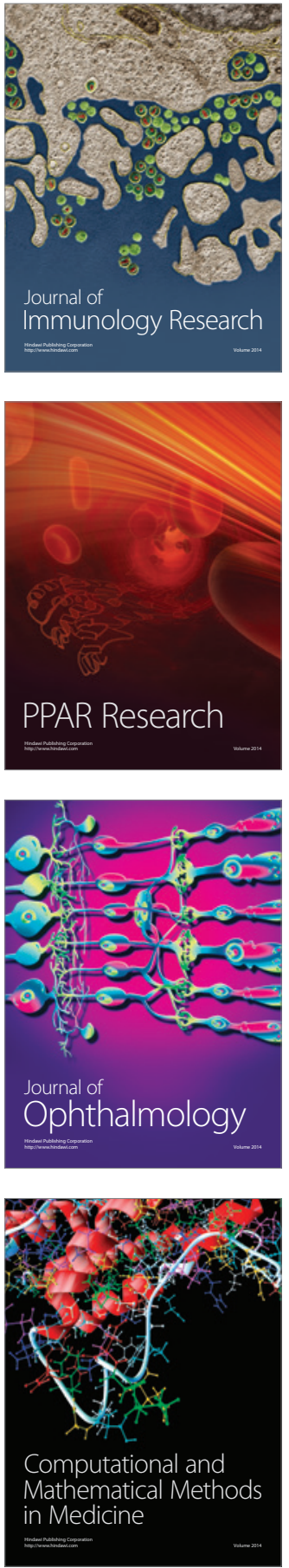

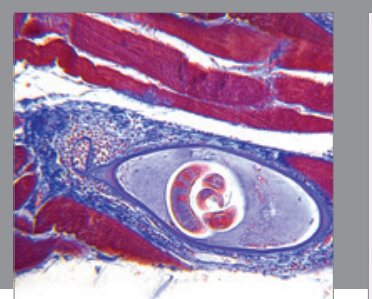

Gastroenterology Research and Practice

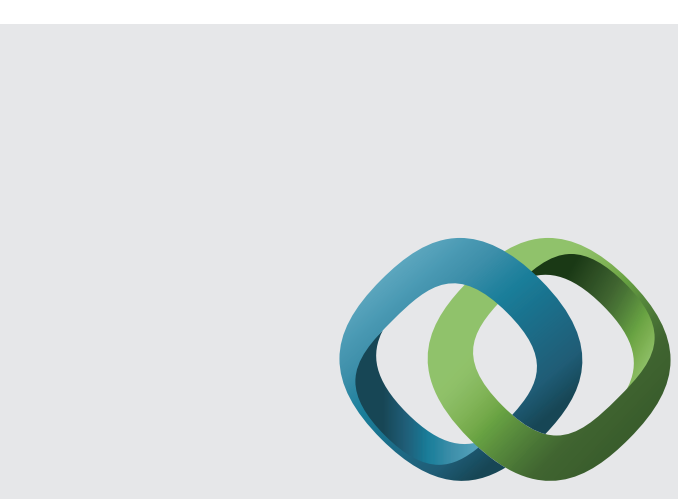

\section{Hindawi}

Submit your manuscripts at

http://www.hindawi.com
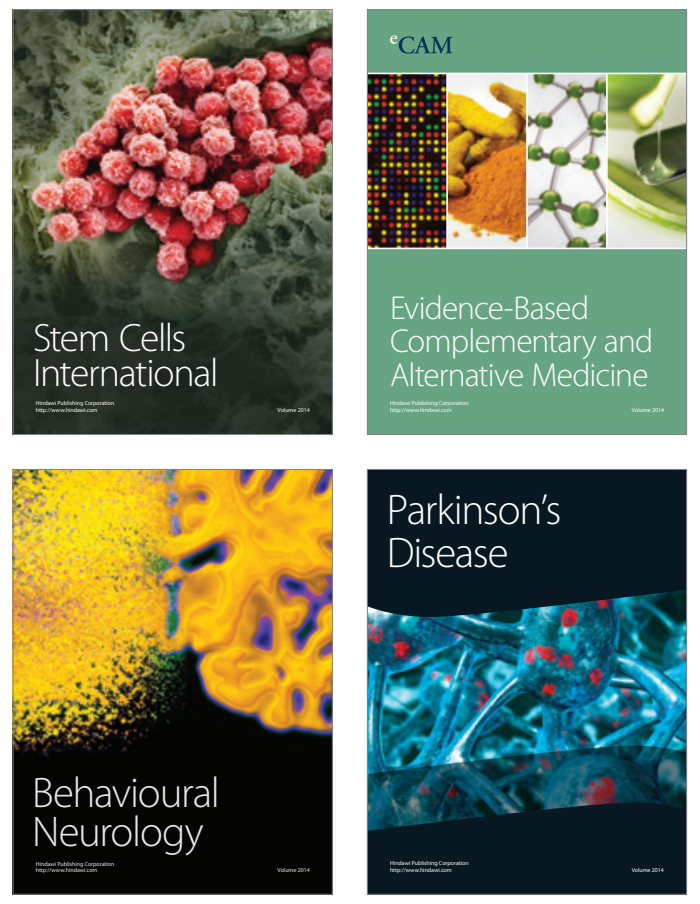
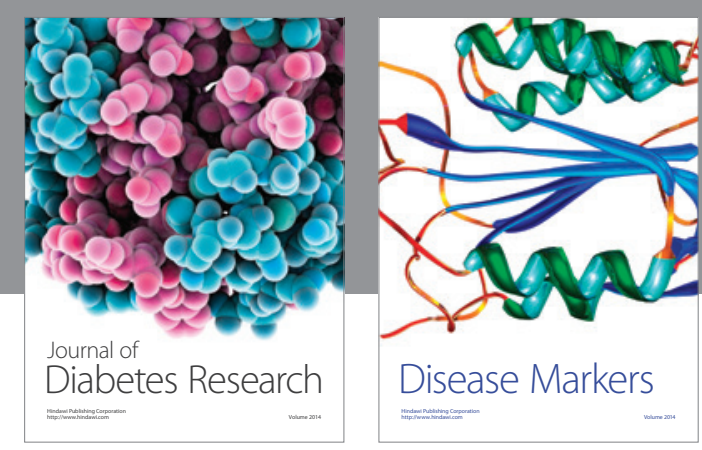

Disease Markers
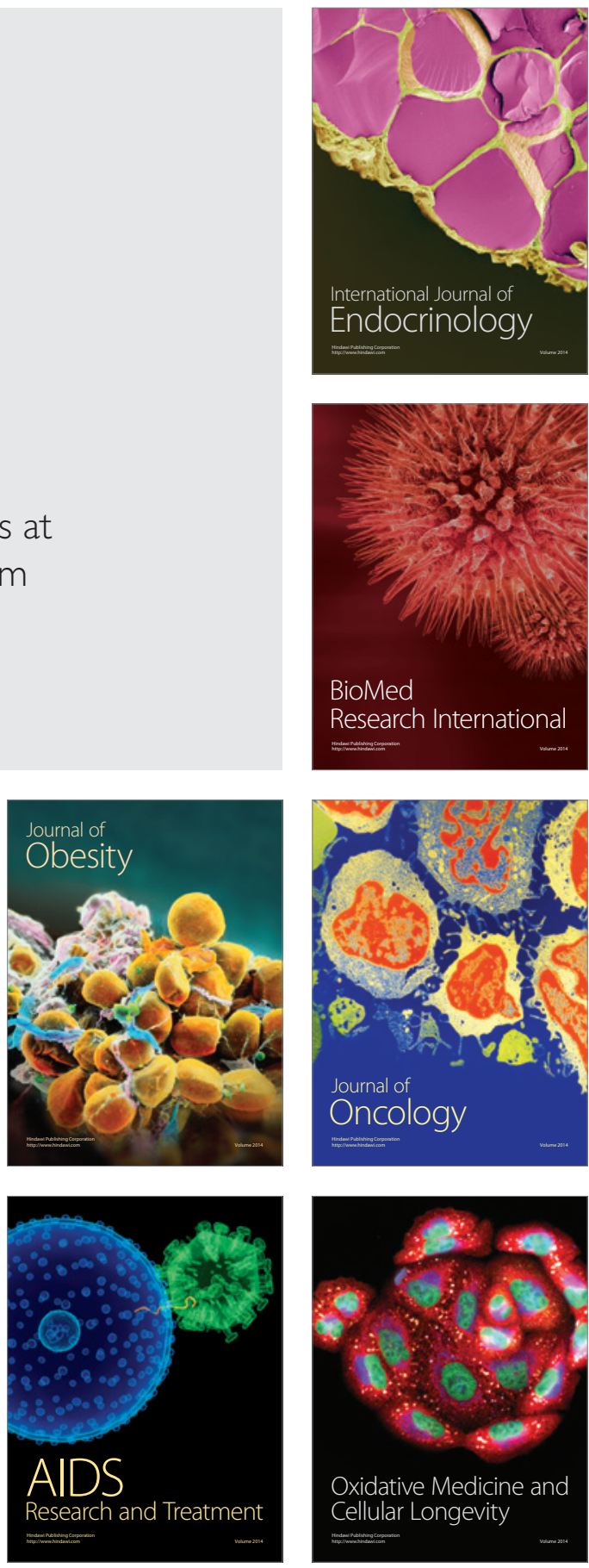